\title{
Autoimmune Rheumatic Disease (Polymyositis and Dermatomyositis) associated with Papillary Thyroid Carcinoma: Report of Two Cases and Review of the Literature
}

\author{
Geeta Lal, Anuradha R Bhama
}

\section{ABSTRACT}

Autoimmune rheumatic diseases, such as polymyositis and dermatomyositis, have been demonstrated to carry a risk of the development of malignancy. Thyroid cancer is a rare occurrence in this setting; however, multiple cases have been reported. We present two cases of papillary thyroid carcinoma associated with dermatomyositis and polymyositis. The first patient is a 64-year-old female found to have papillary thyroid cancer after the diagnosis of polymyositis who underwent thyroid resection. The second patient is a 51-year-old male who was found to have synchronous papillary thyroid cancer and small cell carcinoma of the lung. He did not undergo thyroid resection due to widely metastatic lung cancer. We describe two cases of papillary thyroid cancer associated with autoimmune rheumatic disease. Though it is rare, thyroid cancer should remain in the differential diagnosis of a patient with new onset autoimmune rheumatic disease, as this may alter the eventual management of these patients.

Keywords: Thyroid cancer, Polymyositis, Dermatomyositis, Autoimmune disease, Papillary thyroid cancer.

How to cite this article: Lal G, Bhama AR. Autoimmune Rheumatic Disease (Polymyositis and Dermatomyositis) associated with Papillary Thyroid Carcinoma: Report of Two Cases and Review of the Literature. World J Endoc Surg 2013;5(2):55-58.

Source of support: Nil

Conflict of interest: None

\section{INTRODUCTION}

The association between autoimmune rheumatic disease and malignancy was initially reported in 1916 by Stertz. ${ }^{1}$ Since that time, many authors have explored the link between the two conditions and it has been generally accepted that there is a higher risk of cancer in patients carrying the diagnosis of polymyositis (PM) or dermatomyositis (DM) with a higher rate of malignancy in those with the latter. ${ }^{2,3}$ Thyroid cancer is rarely associated with this syndrome and, in fact, only eight cases have been previously reported in the English literature. We report two cases of papillary thyroid cancer, one associated with DM and the other with PM and highlight potential pitfalls in the management of these patients.

\section{CASE REPORTS}

\section{Case 1}

Patient one is a 64-year-old female who initially presented with a 6 months history of proximal muscle weakness and progressive dysphagia. Physical exam revealed $4 / 5$ strength in the upper extremities and $5 / 5$ strength in the lower extremities with normal reflexes. Initial creatinine kinase was found to be 4,529 U/L (35-150 U/L). Initial immunologic testing was significant for SSA (Sjogren's syndrome A) antibody of 61 units $(<19 \mathrm{U})$, SSB antibody $4 \mathrm{U}(<19 \mathrm{U})$, ANA (antinuclear antibody) screen of $<1: 40(<1: 40)$, and Jo-1 antibody $<1.0(<1.0)$. Subsequent testing revealed antiRNP (ribonuclear protein) antibody of $4 \mathrm{U}(0-19 \mathrm{U})$ and anti-smith antibody of $4 \mathrm{U}(0-19)$. Paraneoplastic autoantibodies (anti-neuronal nuclear abs types 1, 2, and 3; Purkinje cell cytoplasmic Ab types 1, 2 and Tr; amphiphysin $\mathrm{Ab}, \mathrm{CRMP}-5$-IgG, striational (striated muscle) Ab, P/Q-type calcium channel Ab, N-type calcium channel Ab, and ACh receptor (muscle) binding $\mathrm{Ab}, \mathrm{AChR}$ ganglionic neuronal antibody) were all found to be negative. Initial TSH was found to be $1.84 \mu \mathrm{IU} / \mathrm{ml}(0.27-4.2 \mu \mathrm{IU} / \mathrm{ml})$. She was found to have a positive anti-SRP antibody, prompting a malignancy workup. CT scans of the chest, abdomen and pelvis were negative; however, a PET-CT demonstrated a hypermetabolic right thyroid nodule. Subsequent ultrasound confirmed right thyroid nodule measuring $1.6 \mathrm{~cm}$. FNA of this lesion revealed papillary carcinoma. She was evaluated and deemed to be a surgical candidate. She underwent total thyroidectomy with ipsilateral central neck dissection. Bilateral superficial cervical plexus block was used as an adjunct to general anesthesia. Final pathology revealed a $1.5 \mathrm{~cm}$ papillary thyroid carcinoma and a follicular adenoma on the contralateral side. She was monitored in the ICU postoperatively and was discharged home on POD\#2, without exacerbation of her symptoms. Her symptoms from PM were initially improved. However, 23 months postoperatively she experienced an exacerbation of symptoms when placed on a steroid taper. She has continued to undergo extensive treatment for PM, including IVIG and steroids; however, symptoms from PM remain persistent at 
time of this report. Long-term follow-up has revealed no complications from thyroidectomy.

\section{Case 2}

Patient two is a 51-year-old male who presented a facial rash and progressive weakness of his shoulders. This was also associated with progressive dysphagia. On physical examination, he was found to have $4 / 5$ muscle strength in the bilateral upper extremities and $5 / 5$ strength in bilateral lower extremities with normal reflexes. He had undergone imaging workup at an outside facility that revealed a thyroid nodule. Initial creatinine kinase was found to be $338 \mathrm{U} / \mathrm{L}$. Initial immunologic testing was significant for SSA antibody of 3 units, SSB antibody 6 units, ANA screen of $<1: 640$, and Jo- 1 antibody $<1$.0. Subsequent testing revealed doublestranded DNA antibody of $13 \mathrm{IU} / \mathrm{ml}$, anti-RNP antibody of 3 units, and anti-smith antibody of 3 units. Initial TSH was found to be $3.27 \mu \mathrm{IU} / \mathrm{ml}$. He was diagnosed with DM and treated with steroids with some improvement of his symptoms. A malignancy workup was initiated and a PETCT scan was significant for a $2.8 \mathrm{~cm}$ hypermetabolic left thyroid nodule (Fig. 1A), bilateral neck lymphadenopathy and mediastinal lymphadenopathy (Fig. 1B). The thyroid nodule was consistent with papillary cancer on FNA. He was thus referred for consideration of surgical management. Further workup was initiated for the suspicious neck lymphadenopathy as it was noted to be both ipsilateral and contralateral to the primary thyroid tumor. FNA of a supraclavicular node was consistent with metastatic small cell carcinoma of the lung. He was subsequently found to have multiple brain metastases on MRI. Thyroidectomy was deferred and he underwent chemotherapy followed by brain and chest irradiation. Although his DM improved with therapy, he eventually died from progressive lung cancer 17 months after initial diagnosis of DM.

\section{DISCUSSION}

PM and DM are acquired idiopathic myopathies of skeletal muscles characterized by progressive muscle weakness. ${ }^{4}$

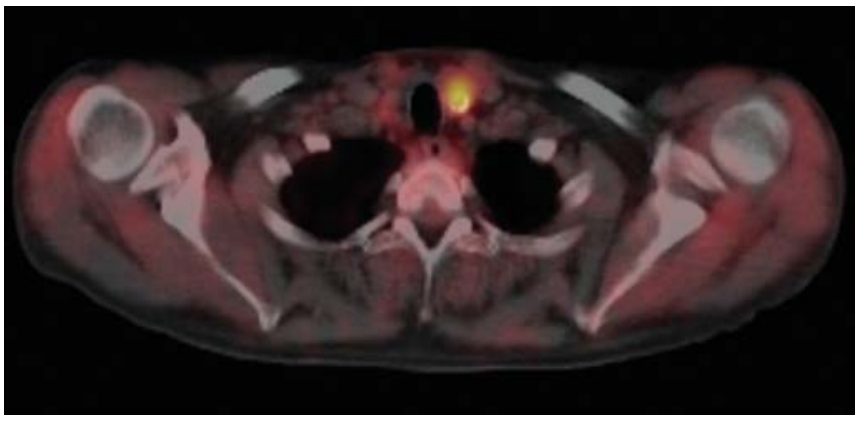

Fig. 1A: PET-CT demonstrating left thyroid nodule (transaxial)
DM is characterized by muscle weakness accompanied by or preceded by a rash. The development of this rash aids in the early diagnosis of DM. PM has a more insidious onset and exact time of diagnosis is difficult to pinpoint. While DM occurs in patients of all ages, PM is limited to those over the age of 18 years, and neither entity carries a familial association. The diagnosis of either disease is made using a combination of clinical features, specific laboratory testing, electromyography and confirmatory muscle biopsy. The treatment consists of a combination of corticosteroids, immunosuppressive agents, immunoglobulin and plasmapheresis. ${ }^{5}$ The incidence of DM and PM is approximately 5.5 per million people. ${ }^{6}$ Long-term survival of PM and DM are similar, and 5 and 10-year estimates are 77 and $62 \%$ respectively. ${ }^{7}$ Cause of death is cardiac or respiratory in nature in a large proportion of patients. ${ }^{7}$ Some patients also develop a malignancy in association with their autoimmune myopathy.

The relationship between autoimmune rheumatic disease and malignancy was first described in 1916 by Stertz, who described a patient with gastric carcinoma and inflammatory muscle disease. ${ }^{1}$ Since that time, several retrospective reviews have confirmed this association. Ovarian, lung, pancreatic, stomach and colorectal cancers are the most common types of solid tumor malignancies associated with DM and PM. ${ }^{3}$ Malignancy occurs in both men and women; however, Chen et al reported a significantly higher association in men on multivariate analysis. ${ }^{8}$ The authors also found that age $>45$ years, the presence of interstitial lung disease, creatine phosphokinase value $>160 \mathrm{U} / \mathrm{L}$ and presence of DM all carried a significantly higher rate of malignancy. ${ }^{8}$

Thyroid cancer has also been reported to occur in the presence of PM/DM, albeit rarely. Similar to other malignancies, thyroid cancer may be diagnosed prior to, during, or after the diagnosis of autoimmune disease. Table 1 summarizes the cases reported in the English literature to date. ${ }^{9-15}$ Seven of eight reported cases of thyroid cancer in this setting have occurred in females and all but

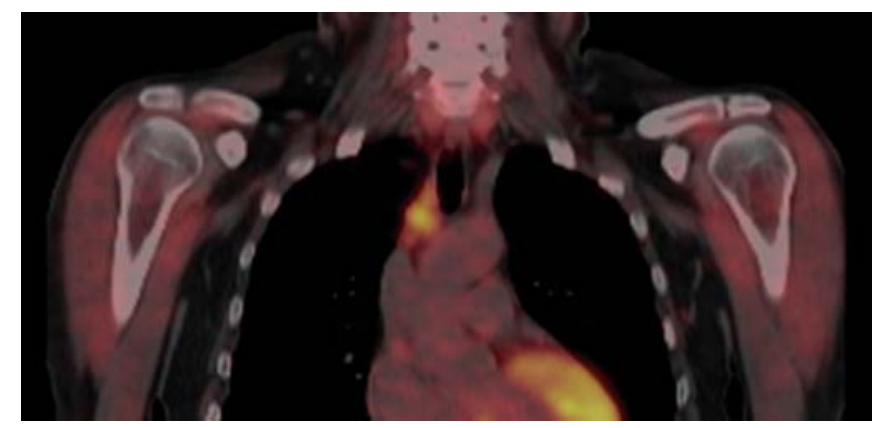

Fig. 1B: PET-CT demonstrating mediastinal lymphadenopathy (coronal) 


\begin{tabular}{|c|c|c|c|c|c|c|c|}
\hline $\begin{array}{l}\text { Author, } \\
\text { year }\end{array}$ & $\begin{array}{l}\text { Patient } \\
\text { age/sex }\end{array}$ & $\begin{array}{l}\text { Dermatomyositis } \\
\text { or polymyositis }\end{array}$ & $\begin{array}{l}\text { Type of } \\
\text { thyroid } \\
\text { malignancy }\end{array}$ & $\begin{array}{l}\text { Pre-existing } \\
\text { thyroid } \\
\text { disease }\end{array}$ & $\begin{array}{l}\text { Thyroid } \\
\text { resection }\end{array}$ & $\begin{array}{l}\text { Timing of cancer } \\
\text { diagnosis in } \\
\text { relation to auto- } \\
\text { immune diagnosis }\end{array}$ & $\begin{array}{l}\text { Resolution } \\
\text { of symptoms } \\
\text { post-thyroidectomy }\end{array}$ \\
\hline $\begin{array}{l}\text { Klink, }{ }^{14} \\
1963\end{array}$ & $27 / \mathrm{M}$ & Polymyositis & Papillary & No & Yes & Post & Not commented \\
\hline $\begin{array}{l}\text { Caron, }{ }^{9} \\
1988\end{array}$ & $74 / F$ & Dermatomyositis & Plasmacytoma & No & Yes & Same & Yes \\
\hline $\begin{array}{l}\text { Hatada, } \\
1996\end{array}$ & $50 / F$ & Dermatomyositis & Papillary & No & Yes & Post & Not commented \\
\hline $\begin{array}{l}\text { Lee, }^{11} \\
2005\end{array}$ & $31 / F$ & Dermatomyositis & Papillary & No & Yes & 4 weeks prior & $\begin{array}{l}\text { Resection prior to } \\
\text { development of auto- } \\
\text { immune disease }\end{array}$ \\
\hline $\begin{array}{l}\text { Kalliabakos, }{ }^{12} \\
2008\end{array}$ & $31 / F$ & Polymyositis & Papillary & $\begin{array}{l}\text { Hashimoto's } \\
\text { thyroiditis }\end{array}$ & Yes & 1.5 years prior & $\begin{array}{l}\text { Resection prior to } \\
\text { development of auto- } \\
\text { immune disease }\end{array}$ \\
\hline $\begin{array}{l}\text { Fujita }^{13} \\
2008\end{array}$ & $54 / F$ & Dermatomyositis & Papillary & No & Yes & Post & Yes \\
\hline \multirow[t]{2}{*}{$\begin{array}{l}\text { Nagashima, }{ }^{15} \\
2009\end{array}$} & $59 / F$ & Dermatomyositis & Papillary & No & No & Post & $\begin{array}{l}\text { Did not undergo } \\
\text { resection }\end{array}$ \\
\hline & $48 / F$ & Dermatomyositis & Papillary & No & No & Post & $\begin{array}{l}\text { Did not undergo } \\
\text { resection }\end{array}$ \\
\hline
\end{tabular}

M: Male; F: Female

one has been papillary thyroid cancer. Caron et al reported a female patient with a plasmacytoma associated with DM. This is the only report of plasmacytoma in the English literature. There has been one case report of a 27 -year-old male with concurrent PM and papillary thyroid carcinoma. ${ }^{14}$ We report the second case of thyroid carcinoma in a male patient with autoimmune rheumatic disease. Our male patient is also unique in that he had papillary thyroid cancer concurrent with an advanced lung malignancy, a tumor that is more typically associated with this syndrome. The only other patient with multiple cancers was reported by Hatada et al in which the 50-year-old female patient had metachronous thyroid cancer and bilateral breast cancer. ${ }^{10}$

The treatment of patients with DM associated with malignancy can be challenging. Firstly, DM in this setting may be more corticosteroid resistant. It is thought that these autoimmune disorders may represent a paraneoplastic event, as their symptoms have been reported to resolve upon resection of any associated cancers and autoimmune symptoms recur upon recurrence of the malignancy. Some authors propose that removal of the coexisting malignancy can improve the DM and/or improve the response rate to steroids ${ }^{16}$ but this is controversial. This issue is even more debated in the setting of thyroid cancer. While some investigators $^{13,16}$ reported improvement of muscle power and CK levels within weeks to months after thyroid resection; others ${ }^{15}$ have reported resolution of symptoms in their patients without surgical treatment. Given the rarity of this condition, formal recommendations regarding thyroid resection do not exist. As such, it is prudent to follow current standard thyroid cancer recommendation guidelines, provided the patient is deemed a reasonable surgical candidate. That being said, our second patient highlights another important issue with these patients, which is the need to rule out any other malignancy more commonly related with DM/PM. While the patient managed by Hatada et al underwent curative resection of all tumors (breast and thyroid), our patient had a widely metastatic and rapidly progressing second malignancy that was not amenable to surgical management. From the standpoint of anesthesia management, it is also important to consider the use of adjunctive regional or local anesthesia techniques and avoid paralytic agents in these often-debilitated patients.

\section{SUMMARY}

We add to the existing literature on the important association of thyroid cancer associated with DM/PM syndromes. Endocrine and other surgeons involved in the care of patients with thyroid tumors must be aware that the association of these syndromes with thyroid cancer is rare and that the underlying malignancy is more likely to be of ovarian or lung origin. Therefore, a diligent search must be made to identify the tumors more commonly associated tumors, as it may alter therapy.

\section{REFERENCES}

1. Stertz G. Polymyositis. Berl Klin Wochenschr 1916;53:489.

2. Sigurgeirsson B, Lindelof B, Edhag O, Allander E. Risk of cancer in patients with dermatomyositis or polymyositis. A population-based study. N E J Med 1992;326:363-67.

3. Hill CL, Zhang Y, Sigurgeirsson B, et al. Frequency of specific cancer types in dermatomyositis and polymyositis: A populationbased study. Lancet 2001;357:96-100. 
4. Dalakas MC, Hohlfeld R. Polymyositis and dermatomyositis. Lancet 2003;362:971-82.

5. Choy EH, Isenberg DA. Treatment of dermatomyositis and polymyositis. Rheumatology 2002;41:7-13.

6. Oddis CV, Conte CG, Steen VD, Medsger TA Jr. Incidence of polymyositis-dermatomyositis: A 20-year study of hospital diagnosed cases in Allegheny County, PA 1963-82. J Rheumatol 1990;17:1329-34.

7. Schiopu E, Phillips K, Macdonald PM, Crofford LJ, Somers EC. Predictors of survival in a cohort of patients with polymyositis and dermatomyositis: Effect of corticosteroids, methotrexate and azathioprine. Arthritis Res Ther 2012; 14:R22.

8. Chen YJ, Wu CY, Shen JL. Predicting factors of malignancy in dermatomyositis and polymyositis: A case-control study. Br J Dermatol 2001;144:825-31.

9. Caron P, Lassoued S, Thibaut I, Fournie B, Fournie A. Thyroid plasmacytoma with dermatomyositis and palmar fasciitis. J Rheumatol 1989;16:997-99.

10. Hatada T, Aoki I, Ikeda H, et al. Dermatomyositis and malignancy: Case report and review of the Japanese literature. Tumori 1996;82:273-75.

11. Lee JH, Kim SI. A case of dermatomyositis associated with papillary cancer of the thyroid gland. Clin Rheumatol 2005;24: 437-38.
12. Kalliabakos D, Pappas A, Lagoudianakis E, et al. A case of polymyositis associated with papillary thyroid cancer: A case report. Cases J 2008;1:289.

13. Fujita M, Hatachi S, Yagita M. Dermatomyositis associated with thyroid cancer. Rheumatol Int 2008;29:203-05.

14. Klink DD, Wachs H. Polymyositis associated with thyroid carcinoma. Report of a case. Neurology 1963;13:160-65.

15. Nagashima T, Onishi S, Kamata Y, Minota S. Dermatomyositis associated with thyroid cancer: A paraneoplastic syndrome. Rheumatol Int 2009;29:1261-62.

16. Carsons $\mathrm{S}$. The association of malignancy with rheumatic and connective tissue diseases. Semin Oncol 1997;24:360-72.

\section{ABOUT THE AUTHORS}

\section{Geeta Lal (Corresponding Author)}

Associate Professor, Department of Surgery, University of Iowa, Iowa USA, Phone: 3193561727, e-mail: geeta-lal@uiowa.edu

\section{Anuradha R Bhama}

Resident, Department of Surgery, University of Iowa, Iowa, USA 